\title{
Transanal irrigation (TAI) in the paediatric population: Literature review and consensus of an Italian multicentre working group
}

\author{
Enrica Caponcelli, ${ }^{1}$ Milena Meroni, ${ }^{2}$ Giulia Brisighelli, ${ }^{3}$ Claudia Rendeli, ${ }^{4}$ Emanuele Ausili, ${ }^{4}$ \\ Piergiorgio Gamba, ${ }^{5}$ Antonio Marte, ${ }^{6}$ Barbara Daniela Iacobelli, ${ }^{7}$ Laura Lombardi, 8 Ernesto Leva, ${ }^{9}$ \\ Paola Midrio10
}

${ }^{1}$ Pediatric Surgery, Policlinico of Modena; ${ }^{2}$ Pediatric Surgery, Bambini Vittore Buzzi Hospital, Milan; ${ }^{3}$ Department Paediatric Surgery, Chris Hani Baragwanath Academic Hospital, University of the Witwatersrand, Johannesburg, South Africa; ${ }^{4}$ Department of Women's, children's and public health Studies, Foundation Policlinico Universitario Agostino Gemelli, IRCCS; 5Pediatric Surgery, University of Padua, Padua; ${ }^{2}$ Pediatric Surgery, Luigi Vanvitelli, University o Campania Luigi Vanvitelli, Naples; ${ }^{7}$ Neuro-urology unit, spina bifida center and Neonatal Surgery Unit, Department of Medical and Surgical Neonatology, Bambino Gesù Children's Hospital, IRCCS, Rome; 8 Pediatric Surgery, Nuovo Ospedale del bambino "P. Barilla", Maggiore Hospital, Parma; ${ }^{9}$ Department of Pediatric Surgery, Fondazione IRCCS Ca' Granda, Ospedale Maggiore Policlinico, Milan; ${ }^{10}$ Pediatric Surgery, Ca' Foncello Hospital, Treviso, Italy

\begin{abstract}
Constipation and fecal incontinence in pediatric patients are conditions due to either functional or organic bowel dysfunction and may represent a challenging situation both for parents, pediatricians, and pediatric surgeons. Different treatments have been
\end{abstract}

Correspondence: Paola Midrio, Pediatric Surgery, Ca' Foncello Hospital, Piazza Ospedale 1, 31100 Treviso, Italy.

Tel.: +39.0422.322298

E-mail: paola.midrio@aulss2.veneto.it

Key words: Transanal irrigation; constipation; incontinence; bowel management.

Contribution: EC: study conceptualization and manuscript writing; GB, LL, EL: design and implementation of the research; CR, EA: manuscript reviewing; PG, AM, BDI, MM: reference search; PM: conceptualization and manuscript reviewing.

Conflict of interest: The authors declare no conflict of interest.

Availability of data and materials: All data generated or analyzed during this study are included in this published article.

Ethics approval and consent to participate: Ethics approval was not required as the study was a review of the literature without participation of patients.

Consent for publication: Written informed consent was obtained from a legally authorized representative(s) for anonymized patient information to be published in this article.

Received for publication: 4 January 2021.

Revision received: 22 March 2021.

Accepted for publication: 20 April 2021.

This work is licensed under a Creative Commons Attribution

NonCommercial 4.0 License (CC BY-NC 4.0).

C Copyright: the Author(s), 2021

Licensee PAGEPress, Italy

La Pediatria Medica e Chirurgica 2021: 43:250

doi:10.4081/pmc.2021.250 proposed throughout the past decades with partial and alternant results and, among all proposed techniques, in the adult population the Transanal Irrigation (TAI) has become popular. However, little is known about its efficacy in children. Therefore, a group of Italian pediatric surgeons from different centers, all experts in bowel management, performed a literature review and discussed the best-practice for the use of TAI in the pediatric population. This article suggests some tips, such as the careful patients' selection, a structured training with expert in pediatric colorectal diseases, and a continuous follow-up, that are considered crucial for the full success of treatment.

\section{Introduction}

Constipation and faecal incontinence are manifestations of bowel dysfunction. Constipation is a very common problem in paediatric age, with a prevalence of $0.7-29.6,{ }^{1}$ and can be related to congenital malformations such as spina bifida (about 60\%), anorectal malformations (about 25\%), Hirschsprung's disease (about 15\%) and sacral agenesis or functional pathologies ${ }^{2}$ such as faecal incontinence. ${ }^{3}$ Pseudoincontinence is a serious condition which affects millions of children and adults worldwide and is commonly caused by stool accumulation. ${ }^{4-6}$

In 1987, Shandling and Gilmour7 introduced the practice of Transanal Irrigation (TAI) to treat constipation and incontinence in children suffering from neurogenic bowel dysfunction. Following its high success rate, TAI became a widespread treatment in adults and children for whom other methods had failed, 8,9 and has now become common practice in those suffering from bowel dysfunction. ${ }^{10-12}$

TAI has been described ${ }^{13}$ as part of a treatment process involving conservative medical treatments, such as dietary measures, use of laxatives, lactulose, polyethylene glycol, suppositories and enemas. ${ }^{14}$ In the paediatric field, TAI shows good success rates ${ }^{15}$ and should be introduced in all bowel rehabilitation programmes prior to undertaking any form of surgical treatment.

The aim of the study was to evaluate the effectiveness of TAI to treat constipation and incontinence and to provide a consensus on its use in paediatric patients. The results are based on the existing liter- 
ature and on the experience of a multicentre group of Italian specialists from various disciplines (i.e. paediatrics, gastroenterology, paediatric surgery, paediatric urology, nephrology and neuro-urology) with proven experience in the field of bowel management and TAI.

\section{Transanal irrigation}

The use of enemas as a bowel management method was developed empirically through the progressive adjustment based on patients' response.

TAI manages to expel faeces by the mechanical action of water or other solutions instilled through the anus into the rectosigmoid and descending colon. The method has been known since $1500 \mathrm{BC}$, and was initially used as a detoxifying procedure of the intestine. In 1979, Chapman proposed children with spina bifida be treated by instilling a saline or soapy solution with a syringe through a rubber catheter, reporting its effectiveness, simplicity, and low cost. ${ }^{16}$ In 1997, it was proposed the intermittent water irrigation, provided by an electric unit functioning as a pump, in order to generate pulsating waves that stimulate the peristalsis and break down the stool. ${ }^{17}$

The enema continence catheter, originally designed by Shandling \& Gilmour $(1987)^{7}$ for patients with spina bifida, is a catheter with an inflatable balloon on one end. The catheter is inserted into the rectum and the balloon is inflated to keep it in place and avoid fluid loss during infusion. The washing liquid works by gravity alone. At the end of the procedure, the balloon is deflated and the catheter removed to allow the faeces to be expelled. The method is effective but requires the presence of a caregiver. The reference device of the current review ${ }^{18}$ consists of a control unit, a manual pump connected to a balloon catheter, and a bag to be filled with warm tap water.

\section{Literature Review}

\section{Materials and Methods}

A group of experts (paediatricians and paediatric surgeons) from 10 Italian centres with experience in the treatment of constipation and neurogenic bowel reviewed the current literature.

English papers published between January 1981 and November 2017 on the use of TAI in children and adolescents with intestinal dysfunctions (i.e. incontinence or constipation related to anorectal malformation, Hirschsprung's disease, neurogenic intestine) were selected using PubMed (Table 1). The following keywords were used: "transanal irrigation" OR "rectal irrigation" OR "anorectal irrigation" OR "neurogenic bowel dysfunction" AND "children" OR "child" OR "paediatric" OR "pediatric". The articles were selected by two of the authors to avoid sampling bias.

\section{Inclusion criteria}

i) Patient age $<18$ years; ii) Long-term use of TAI as a procedure for expelling stool; iii) TAI performed with methods that include hydrostatic pressure, use of syringe, manual pump.

\section{Exclusion criteria}

i) Patient age $>18$ years; ii) Series with a prevalence of adult patients; iii) Use of TAI for acute disimpaction; iv) Patients who perform antegrade irrigation; v) Letters to the editors.

Table 1. Literature review.

\begin{tabular}{|c|c|c|}
\hline Authors & Number of patients & Number of patients who improved with TAI (\%) \\
\hline Ausili et al. ${ }^{19}$ & 60 & $56(93)$ \\
\hline Blair et al. ${ }^{20}$ & 23 & $20(87)$ \\
\hline Choi et al. ${ }^{21}$ & 47 & $43(91)$ \\
\hline Corbett et al. 15 & 21 & $20(95)$ \\
\hline Eire et al.22 & +2 & $32(97)$ \\
\hline King et al. ${ }^{23}$ & +2 & $8(40)$ \\
\hline Liptak and Revell24 & $\sqrt{20}$ & $15(94)$ \\
\hline Lopez Pereira et al. ${ }^{4}$ & 25 & $25(100)$ \\
\hline Märzheuser et al. 25 & 38 & $32(84)$ \\
\hline Matsuno et al. ${ }^{26}$ & 13 & $10(77)$ \\
\hline Mattsson and Gladh 27 & 40 & $35(88)$ \\
\hline Midrio et al. 12 & 78 & $78(100)$ \\
\hline Nasher et al.28 & 10 (7 CIC, 1 MAR, 2 HD) & $10(100)$ \\
\hline $\mathrm{Ng}$ et al.29 & 31 & $26(84)$ \\
\hline Peña et al. ${ }^{30}$ & 172 (44 constipation, 128 incontinent) & $\begin{array}{l}41 / 44(93) \\
113 / 128(88)\end{array}$ \\
\hline Shandling and Gilmour 31 & 112 & $112(100)$ \\
\hline Scholler-Gyere et al. 32 & 41 & $27(66)$ \\
\hline Vande Velde et al. ${ }^{33}$ & 24 & $21(88)$ \\
\hline Walker and Webster ${ }^{34}$ & 12 & $8(67)$ \\
\hline Willis 35 & 100 (11 constipation, 43 MMC, 46 ARM) & $\begin{array}{l}\text { Constipation: } 11 \text { improved (100) } \\
\text { MMC: } 32 \text { improved, } 10 \text { spontaneous defaecation, } 1 \text { soiling (98) } \\
\text { ARM: } 35 \text { improved, } 8 \text { spontaneous defaecation (93) }\end{array}$ \\
\hline Total & 916 & $817(89)$ \\
\hline
\end{tabular}

CIC: intermittent bladder catheterization; ARM: anorectal malformation; HD: Hirschsprung's disease; MMC: myelomeningocele. 


\section{Results}

Twenty articles that met the inclusion criteria (shown in Table 1) were selected, for a total of 916 patients. About half of the articles analysed patients and families' quality of life (QoL) but data were not comparable as tests and parameters were different among the papers. In particular, 12 articles noted an improvement in QoL, 7 did not deal with the issue, and 1 reported no improvement. In some papers, the time required to perform TAI is considered a disincentive to continue the procedure; in others, the increase of autonomy and independence of the patient is cited as an encouraging factor.

In the review, $89 \%$ of patients showed clinical improvement (i.e. increased degree of continence and reduction of episodes of encopresis) after introducing TAI, thus underlining its effectiveness.

\section{Indications and contraindications}

TAI is recommended in children with neurogenic bowel as a consequence of acquired or congenital spinal defects, surgical outcomes of Hirschsprung's disease, anorectal malformations, and idiopathic constipation resistant to medical therapy. ${ }^{36}$ The urge to initiate TAI is often due to the failure of other bowel emptying methods or the need to improve the bowel management in terms of time, autonomy, and effectiveness. ${ }^{12,37}$ Absolute and relative contraindications to TAI are listed in Table 2.

The patient's responsiveness to TAI is determined not only by a correct indication, but also by factors such as the parental compliance, the psychological implications, and the patient's motivations. The approach to TAI of a patient who can already artificially empty his bowel and is looking for an improvement will differ from that of a patient for whom conservative methods have proven unsuccessful. The introduction of TAI should be personalized for each patient based on clinical history, previous surgery, type of stool, symptoms, ongoing therapy, diet, age, ability to walk and manipulate objects.

\section{Clinical examination and preparation}

TAI treatment is proposed to patients during a patient-tailored multidisciplinary team meeting, involving the patient and his/her family, dedicated nurse specialists, a specialized doctor and a phycologist familiar with the paediatric/adolescent population. A further meeting one week apart is often organized, if requested, to shed light on possible patient's doubts, to answer questions and to encourage perseverance in the early stages of the program in order to maximize adherence to the treatment and possibility of success. There are no significant differences in caring for in different patients age groups. Support and assistance in the early stages are mainly tailored according to patient's mental and emotional maturity.

A rectal examination is essential to exclude any anal disorders, ascertain there is no faecaloma in the ampulla, and assess the sphincter tone. Faecalomas must be eliminated before undertaking any TAI programme; 9 conversely, in the absence of faecal impaction, TAI may start immediately. However, patients suffering from chronic constipation or spinal cord injuries most often require colon cleansing before starting TAI, due to the poor efficacy of conservative treatments (i.e. faecal softeners, laxatives, enemas, suppositories, digital evacuation). We recommend performing the preliminary emptying with 2-3 rectoclysis per day (one with saline solution, one with saline solution and phosphate, and another with saline solution and petroleum jelly) until the colon is completely cleansed. The results should be checked radiologically.

\section{How to perform TAI}

TAI is a system that allows faeces to be expelled by introducing water (or other solutions) into the descending colon through the anus in order to clean the rectosigmoid tract. Caregivers are trained how to perform the procedure and how to train patients to become more independent over time. 38

The irrigation is performed by using either a lubricated Foley catheter or a rectal catheter. The Foley is preferable as it is softer, atraumatic, and the balloon, inflated with $10 \mathrm{cc}$ of water in the rectum, prevents any leakage of the solution, optimizing the result. The solution should be introduced slowly, so as to take about 5 minutes, in order to avoid rapid intestinal distension, and it should be at a temperature of $37-38{ }^{\circ} \mathrm{C}$ to avoid abdominal cramps. The water should be preferably inserted by connecting the catheter to an enema bag positioned about one metre above the level of the patient.

The solution is diversified for each patient, both in terms of composition and quantity, and this information is obtained through several attempts. It can be start with just tap water $(10 \mathrm{~mL} / \mathrm{kg})$, and increase the volume (up to $20 \mathrm{~mL} / \mathrm{kg}$ ) or add sodium chloride (one teaspoon in $500 \mathrm{cc}$ of water to obtain an osmolarity similar to that of body fluids) should the tap water alone achieve no results. ${ }^{25}$ Other components may be added, such as petroleum jelly, Castile soap, glycerine, and phosphate. The required volume depends on the type of colon: in case of a distended and hypomobile colon, high quantity solutions are required $(20 \mathrm{~mL} / \mathrm{kg}$ of water or salt water in the doses described above), and in case of a non-distended and hypermobile colon, a low volume solution $(10 \mathrm{~mL} / \mathrm{kg}) \mathrm{com}-$ bined with a constipating diet may is recommended. ${ }^{30}$ The concentration of solutes varies according to the results, especially to reduce possible side effects, such as nausea or abdominal pain.

TAI may be administered with the patient in different positions: on the left side (with the left leg extended and the right one bent at the chest), in fetal position, or supine. Patients are instructed to hold in the fluid for at least 10 minutes and then expel the stool. The entire procedure should not exceed 40 minutes and should be performed in a suitable environment, i.e. the bathroom. It is recommended not to reward children after the procedure, so that they may accept the mechanical emptying of their bowel as a "natural" practice.

Table 2. Contraindications for TAI.

\begin{tabular}{|c|c|}
\hline Absolute contraindications & Relative contraindications \\
\hline Inflammatory bowel diseases & Long term steroid therapy \\
\hline Colonic stenosis & Pelvic radiotherapy \\
\hline
\end{tabular}




\section{Complications}

There are documented risks associated with TAI, including systemic reactions to the irrigation and rectal perforation, 39,40 although they are very rare (estimated risk of 1/50000, 0.02\%). ${ }^{11}$ Latex allergy must be excluded before proceeding. Perforation can occur by direct action of the rectal catheter, excessive inflation of the balloon, or excessive hydrostatic pressure during the irrigation. In order to address these complications, the use of a Foley catheter is recommended instead of a more rigid rectal catheter, to check the volume of the balloon outside the rectum and not to exceed the pressure during irrigation. Phosphate based enemas can lead to potentially fatal side effects: electrolyte disturbances (hyperphosphataemia, hypernatremia, hypocalcemia) and severe dehydration. Retention of the phosphate solution with prolonged reabsorption or reduced renal excretion of phosphate may result in hyperphosphataemia and subsequent hypocalcaemia and lethal acidosis. ${ }^{41}$

In order to reduce the risk of complications, caregivers must be adequately trained by competent personnel, and signs and symptoms (such as abdominal pain, sweating, chills, general discomfort, dizziness, nausea) leading to complications should be elucidated in order to recognize and manage them (Figure 1). Thanks to detailed explanations and training on how to perform the TAI procedure safely, patients are usually available to adopt the practice. In case of anxious, embarrassed or feared patients, a further multidisciplinary meeting is organized in order to encourage patients in facing their fears and becoming more and more familiar with TAI treatment. So far, no drop-out among paediatric and adolescent population have been recorded.

\section{Conclusions}

bowel dysfunctions can be secondary to a variety of clinical conditions, including: Hirschsprung's disease, anorectal malformations, spina bifida and intractable constipation. Constipation and faecal incontinence represent a spectrum of severity that can differ from case to case. Simple dietary measures may be sufficient in milder forms, but hospitalization may be required for the severe forms. Intractable constipation is a disabling condition for a child, with consequences on his quality of life and socialization. The discomfort this condition may induce can lead to absenteeism from school and other social activities. Furthermore, the need for therapies and treatments influences family life and the life of their caregivers, resulting in a significant financial commitment.

There is currently no unanimous consensus on how to deal with bowel dysfunctions in paediatric patients. We believe this study shows that there are the prerequisites to encourage a structured and personalized approach to treat patients who suffer from organic or functional constipation. As previously mentioned, in order to define an adequate treatment plan, the personal and clinical history of each patient must be taken into consideration together with their condition to date and their radiological data. Each child must receive a personalised bowel management programme, adjusting his diet, motor activity, use of laxatives and/or TAI, that improves the bowel function, reduces the related infections and the time spent for bowel emptying.

The data collected in our review were mainly retrospective and with a follow-up of variable length. Prospective studies on TAI in children should be conducted for further investigation.

The social impact and quality of life of the families of patients

\begin{tabular}{|ll|}
\hline & \multicolumn{1}{c}{ Indications } \\
- & Instipation \\
- & Pseudinence \\
\hline
\end{tabular}

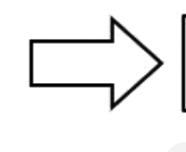

Evaluation of possible contraindications
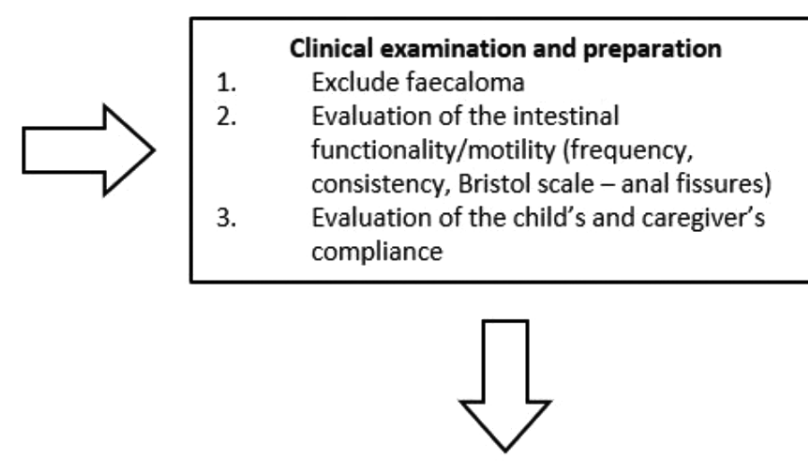
Outpatient follow-up (every month for the first 3 months, alternate months for other 6 months)

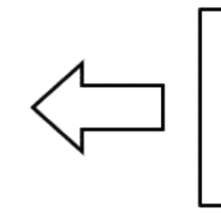

\section{TAl training}

First irrigation, supervised by an experienced health care professional

- Trial and error method for the identification of the adequate lavage fluid composition

In case of good results with

TAl, a self-administration system can be introduced,

Figure 1. Flow chart representing the steps to follow when TAI is prescribed. 
who need assistance for bowel management have not been fully assessed. The effectiveness of TAI for these patients suggests it can be used both in patients for whom other treatment programmes failed as well as a first-line treatment. TAI is usually well tolerated and has a low incidence of major side effects. Individual training assisted by qualified personnel guarantees the best results. It is important to constantly support these patients in order to limit the possible drop-out in the long-term.

The need for a multidisciplinary management of patients suffering from bowel disorders due to surgical, malformative or acquired conditions call for the creation of paediatric colorectal centres.

\section{References}

1. Mugie SM, Benninga MA, Di Lorenzo C. Epidemiology of constipation in children and adults, a systematic review. Best Pract Res Clin Gastroenterol 2011;25:3-18.

2. Chase JW, Homsy Y, Siggaard C, et al. Functional constipation in children. J Urol 2004;171:2641.

3. Rajindrajith S, Devanarayana NM, Benninga MA. Review article: faecal incontinence in children: epidemiology, pathophysiology, clinical evaluation and management. Aliment Pharmacol Ther 2013;37:37-48.

4. López Pereira P, Salvador OP, Arcas JA, et al. Transanal irrigation for the treatment of neu-ropathic bowel dysfunction. J Pediatr Urol 2010;6:134-8.

5. Pena A, Guardino K, Tovilla JM, et al. Bowel management for fecal incontinence in patients with anorectal malformations. J Pediatr Surg 1998;33:133-7.

6. Keshtgar AS, Ward HC, Clayden GS, de Sousa NM. Investigations for incontinence and constipation after surgery for Hirschsprung's disease. Ped Surg Int 2003;19:4-8.

7. Shandling B, Gilmour RF. The enema continence catheter in spina bifida: successful bowel management. J Pediatr Surg 1987;22:271-3

8. Del Popolo G, Mosiello G, Pilati C, et al. Treatment of neurogenic bowel dysfunction using transanal irrigation: a multi center Italian study. Spinal Cord 2008;46:517-22.

9. Emmanuel A. Review of the efficacy and safety of transanal irrigation for neurogenic bowel dysfunction. Spinal Cord 2010;48:664-73.

10. Bray L, Sanders C. An evidence-based review of the use of transanal irrigation in children and young people with neurogenic bowel. Spinal Cord 2013;51:88-93.

11. Christensen P, Krogh K, Buntzen S, et al. Long-term outcome and safety of transanal irriga-tion for constipation and fecal incontinence. Dis Colon Rectum 2009;52:286-92.

12. Midrio P, Mosiello G, Ausili C, et al. Peristeen ${ }^{\circledR}$ transanal irrigation in pediatric patients with anorectal malformations and spinal cord lesions: a multicentre Italian study. Colorectal Dis 2016; 18:86-93.

13. Emmanuel AV, Krogh K, Bazzocchi G, et al. Consensus review of best practice of transanal irrigation in adults. Spinal Cord 2013;51:732-8.

14. Coggrave M. Neurogenic continence. Part 3: bowel management strategies. Br J Nurs 2008;17:962-8.

15. Corbett P, Denny A, Dick K, et al. Peristeen integrated transanal irrigation system success-fully treats fecal incontinence in children. J Pediatr Urol 2014;10:219-22.

16. Chapman W, Hill M, Shurtleff DB. Management of neurogenic bowel and bladder. Oak Brook, ILL: Eterna Press; 1979.
17. Puet TA, Jackson H, Amy S. Use of pulsed irrigation evacuation in the management of the neuropathic bowel. Spinal Cord 1997;35:694-9.

18. Christensen P, Bazzocchi G, Coggrave M, et al. A randomized controlled trial of transanal irrigation versus conservative bowel management in spinal cord-injured patients. Gastroenterology 2006;131:738-47.

19. Ausili E, Focarelli B, Tabacco F, et al. Transanal irrigation in myelomeningocele children: an alternative, safe and valid approach for neurogenic constipation. Spinal Cord 2010;48:560-5.

20. Blair GK, Djonlic K, Fraser GC, et al. The bowel management tube: an effective means for controlling fecal incontinence. J Pediatr Surg 1992;27:1269-72.

21. Choi EK, Shin SH, Im YJ, et al. The effects of transanal irrigation as a stepwise bowel man-agement program on the quality of life of children with spina bifida and their caregivers. Spinal Cord 2013;51:384-8.

22. Eire PF, Cives RV, Gago MC. Faecal incontinence in children with spina bifida: the best conservative treatment. Spinal Cord 1998;36:774-6.

23. King SK, Stathopoulos L, Pinnuck L,et al. Retrograde continence enema in children with spina bifida: not as effective as first thought. J Paediatr Child Health 2017;53:386-90.

24. Liptak GS, Revell GM. Management of bowel dysfunction in children with spinal cord dis-ease or injury by means of the enema continence catheter. J Pediatr 1992;120:190-4.

25. Märzheuser S, Karsten K, Rothe K. Improvements in incontinence with self-management in patients with anorectal malformations. Eur J Pediatr Surg 2016;26:186-91.

26. Matsuno D, Yamazaki Y, Shiroyanagi Y, et al. The role of the retrograde colonic enema in children with spina bifida: is it inferior to the antegrade continence enema? Pediatr Surg Int 2010;26:529-33.

27. Mattsson S, Gladh G. Tap-water enema for children with myelomeningocele and neurogenic bowel dysfunction. Acta Paediatr 2006;95:369-74.

28. Nasher O, Hill RE, Peeraully R, et al. Peristeen (C) transanal irrigation system for paediatric faecal incontinence: a single centre experience. Int J Pediatr 2014;2014:954315.

29. Ng J, Ford K, Dalton S, et al. Transanal irrigation for intractable faecal incontinence and constipation: outcomes, quality of life and predicting non-adopters. Pediatr Surg Int 2015;31:729-34.

30. Peña A, Guardino K, Tovilla JM, et al. Bowel management for fecal incontinence in patients with anorectal malformations. J Pediatr Surg 1998;33:133-7.

31. Shandling B, Gilmour RF. The enema continence catheter in spina bifida: successful bowel management. J Pediatr Surg 1987;22:271-3.

32. Schöller-Gyüre M, Nesselaar C, van Wieringen H, van Gool JD. Treatment of defecation disorders by colonic enemas in children with spina bifida. Eur J Pediatr Surg 1996;6 Suppl $1: 32-4$.

33. Vande Velde S, Van Biervliet S, Van Renterghem K, et al. Achieving fecal continence in pa-tients with spina bifida: a descriptive cohort study. J Urol 2007;178:2640-4.

34. Walker J, Webster P. Successful management of faecal incontinence using the enema conti-nence catheter. $\mathrm{Z}$ Kinderchir 1989;44:44-5.

35. Willis RA. Faecal incontinence--Willis Home Bowel Washout Programme. Z Kinderchir 1989;44:46-7.

36. Velde SV, Biervliet SV, Bruyne RD, Winckel MV. A systematic review on bowel manage-ment and the success rate of the var- 
ious treatment modalities in spina bifida patients. Spinal Cord 2013;51:873-81.

37. Koppen IJ, Kuizenga-Wessel S, Voogt HW, et al. Transanal irrigation in the treatment of children with intractable functional constipation. J Pediatr Gastroenterol Nutr 2017;64: 225-29.

38. Norton C. Guidelines for the use of rectal irrigation for healthcare professionals. St Mark's Hospital and Burdett Institute of Gastrointestinal Nursing editor, 2009.
39. Biering-Sorensen F, Bing J, Berggreen P, Olesen GM. Rectum perforation during transanal irrigation: a case story. Spinal Cord 2009;47:266-7.

40. Paran H, Butnaru G, Neufel D, et al. Enema-induced perforation of the rectum in chronically constipated patient. Dis Colon Rectum 1999;42:1609-12.

41. Marek I, Benz K, Kusnik S, et al. Phosphate intoxication after application of enema--a life-threatening iatrogenic complication. Klin Padiatr 2015;227:235-8. 